\title{
Overland flow hydrodynamic characteristics at low Reynolds number with roughness bed
}

\author{
pu li ${ }^{1}$, kuandi zhang ${ }^{1}$, jingwen wang $^{1}$, and he meng ${ }^{1}$ \\ ${ }^{1}$ Northwest A\&F University
}

April 28, 2020

\begin{abstract}
Overland flow is the major contributor to soil erosion. To clarify the hydrodynamic characteristics of overland flow at small Reynolds number, indoor experiments with fifteen unit-width flow discharges from $0.069 \times 10-3 \mathrm{~m} 2 \cdot \mathrm{s}-1$ to $2.5 \times 10-3 \mathrm{~m} 2 \cdot \mathrm{s}-1$, five slope gradients from $5.23 \%$ to $25.88 \%$, three surface roughnesses and two kinds of flow ( $80 \%$ glycerol and water mixed flow and water flow) were systematically investigated. Results showed that mean depth and mean flow velocity can be good predicted by unit-width flow discharge, slope gradient and surface roughness. Based on flow regime criterion of parameter m, for $80 \%$ glycerol and water mixed flow, the flow regime was laminar flow. For water flow, it was between laminar flow and turbulent flow. According to the transitional Fr of 1, the experimental flow state tended to subcritical laminar flow with the increase of surface roughness. For $80 \%$ glycerol and water mixed flow, parameter K was 57 . For water flow, parameter K was increased with the increase of surface roughness and fluctuated as slope gradient increased. The resistance law of open channel hydraulic for laminar flow ( $\mathrm{f}=96 / \mathrm{Re}$ ) is not suitable for overland flow. In general, resistance coefficient had a good power function with Re. Meanwhile, there was a high significant correlation between resistance coefficient and inundation ratio and slope gradient. Resistance coefficient decreased as inundation ratio and slope gradient increased. For all flow regime in this study, a more accurate resistance coefficient prediction model was established by multiple regression analysis. As for hydrodynamic parameters, shear stress had a positive correlation with surface roughness. Meanwhile, stream power is not affected by increasing surface roughness, while unit stream power was negative with surface roughness. The slope gradient played a more important role in increasing the flow energy.
\end{abstract}

\section{Hosted file}

Overland flow hydrodynamic characteristics at low Reynolds number with roughness bed.docx available at https : //authorea.com/users/313584/articles/444353-overland-flow-hydrodynamic-characteristicsat-low-reynolds-number-with-roughness-bed 


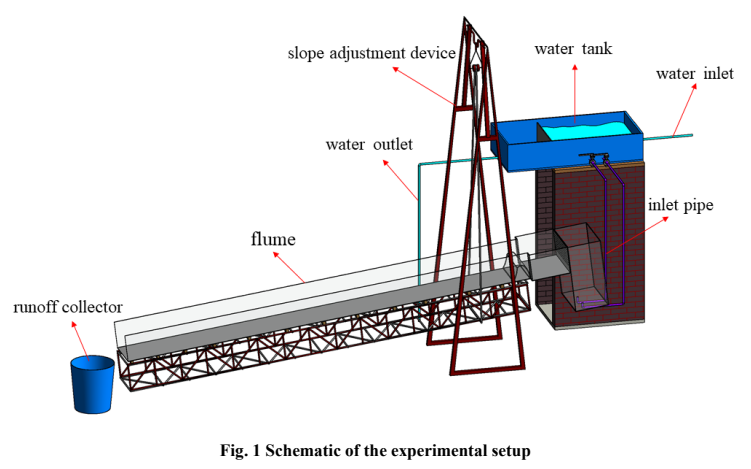



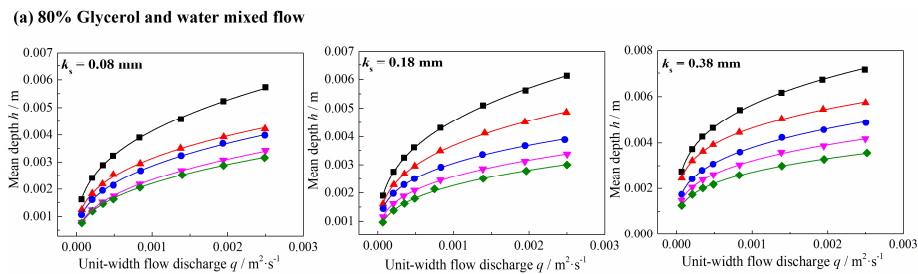

(b) Water flow

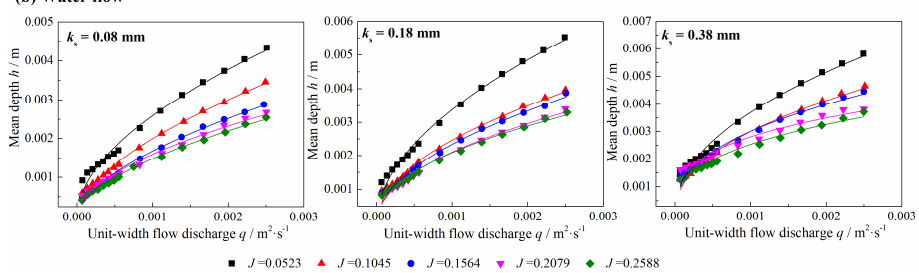

Fig. 2 The mean depth 

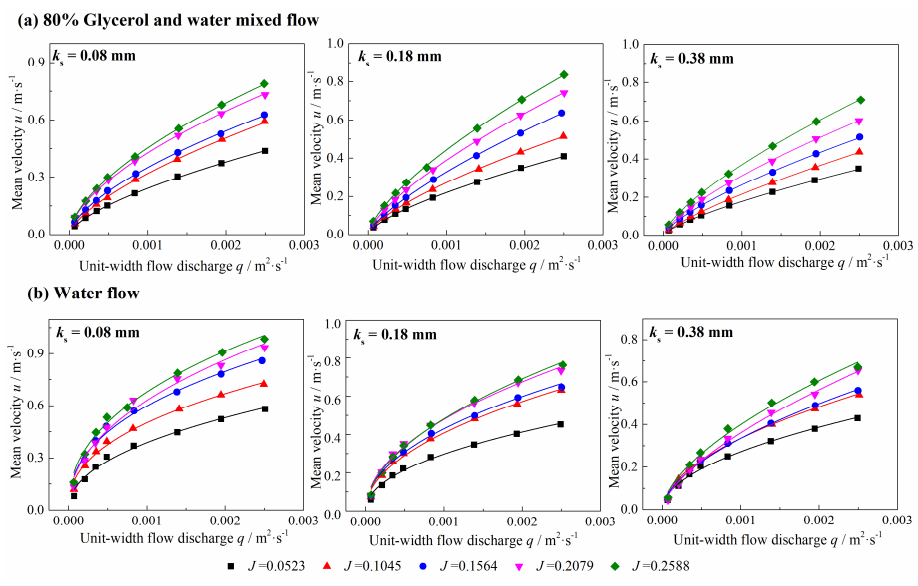

Fig. 3 The mean velocity 

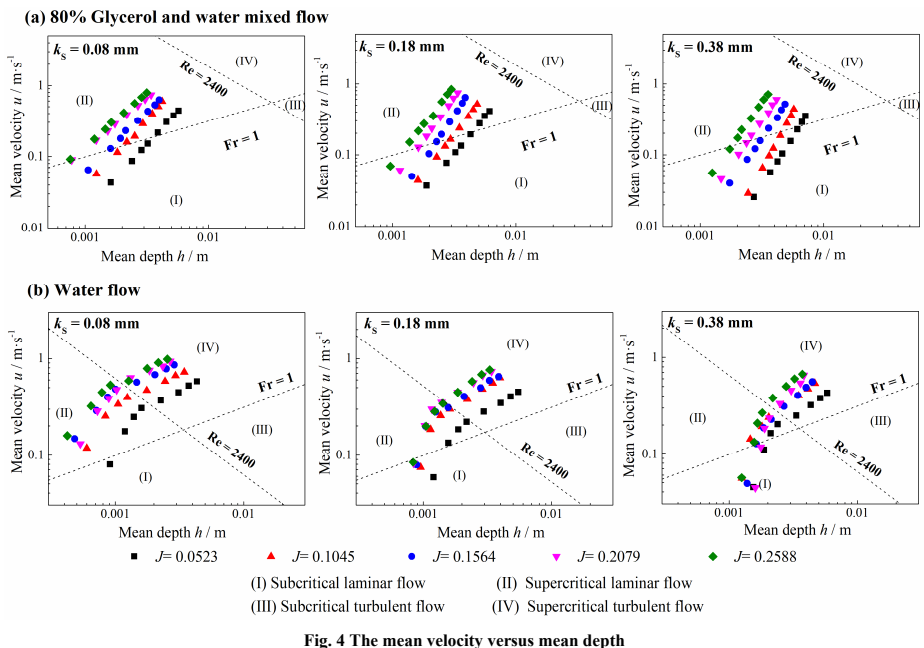

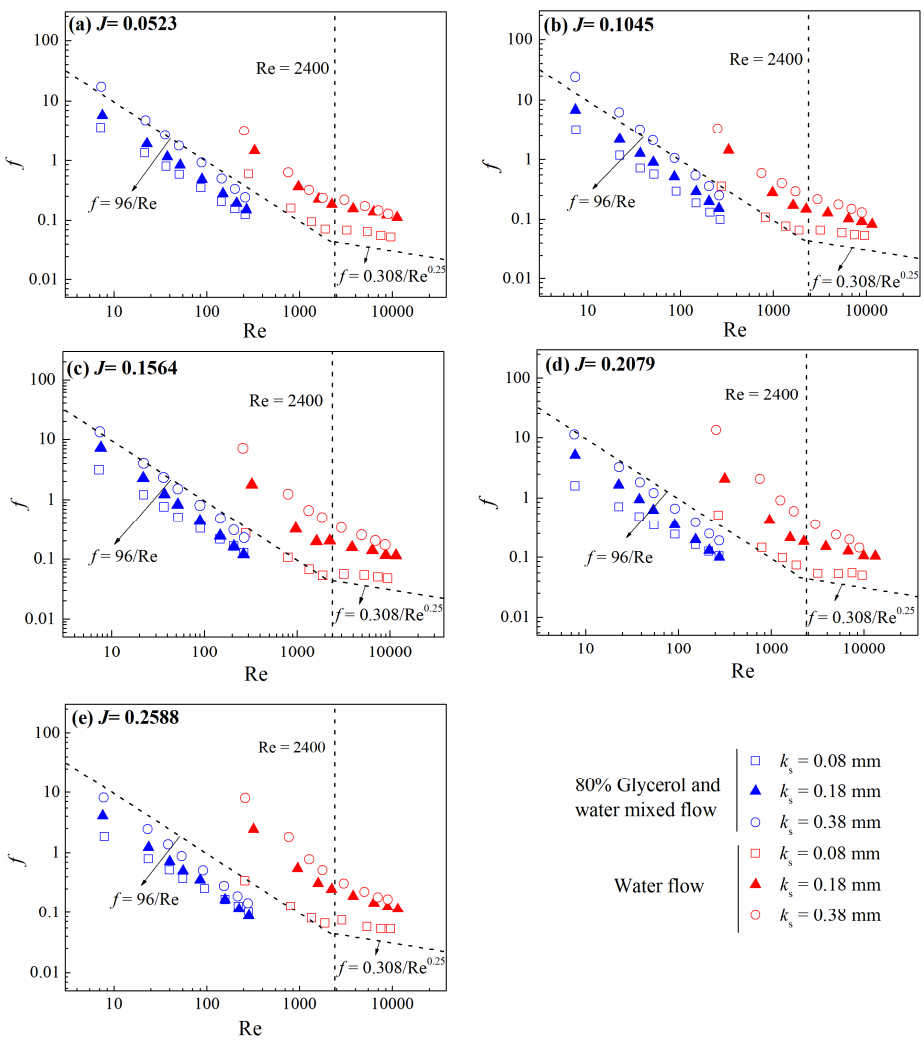

Note: The dash line $(f=96 / \mathrm{Re})$ represents the relationship between $f$ and Re in open channel flow at laminar condition. The dash line $\left(f=0.308 / \operatorname{Re}^{0.25}\right.$ ) represents the relationship between $f$ and $\operatorname{Re}$ within $2,400<\operatorname{Re}<20,000$ (Savat, 1980).

Fig. 5 The relationship between $f$ and Re 

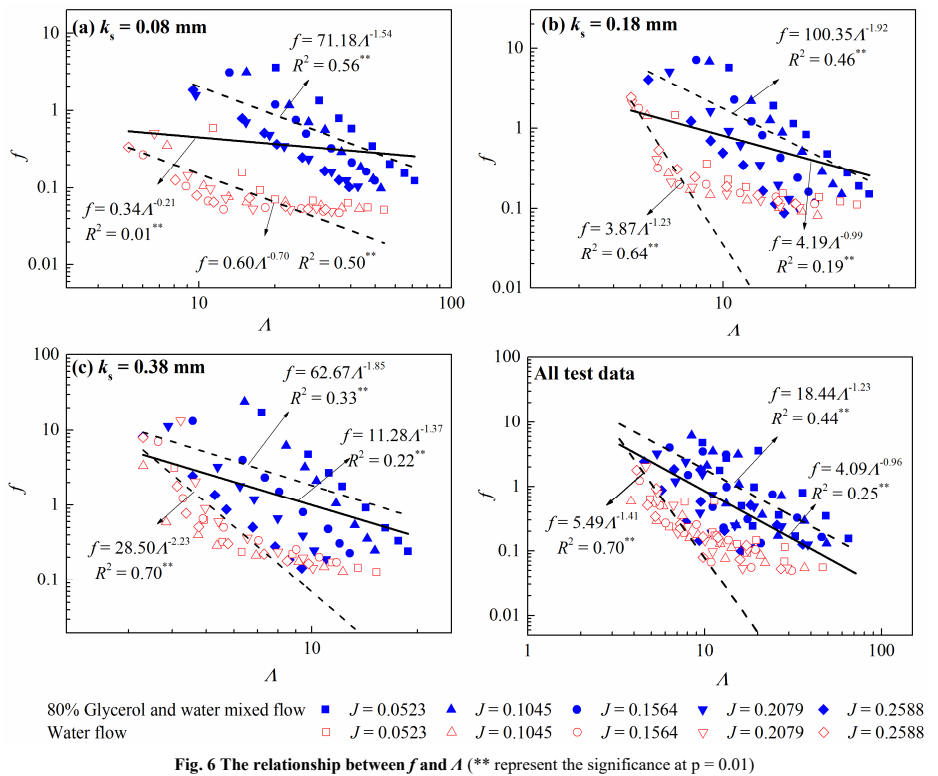


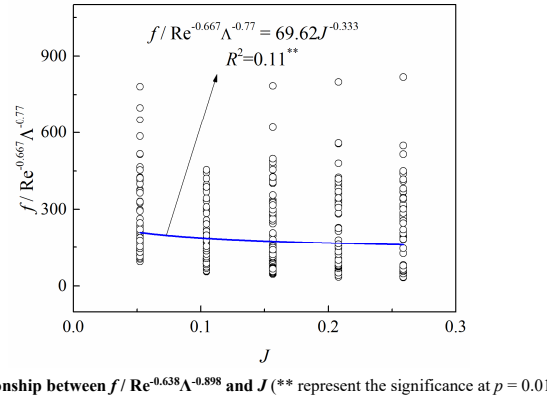

Fig. 7 The relationship between $\boldsymbol{f} / \mathbf{R e}^{-0.638} \Lambda^{-0.998}$ and $J\left({ }^{* *}\right.$ represent the significance at $\left.p=0.01\right)$ 


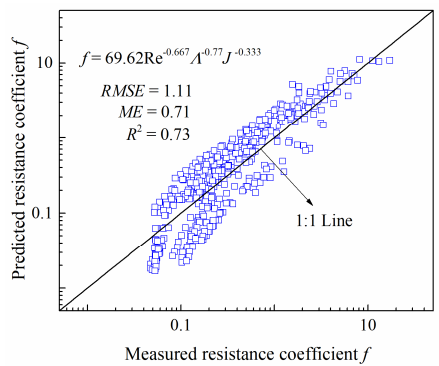

Fig. 8 Predicted resistance coefficient versus the measured value using Eq. (22) 

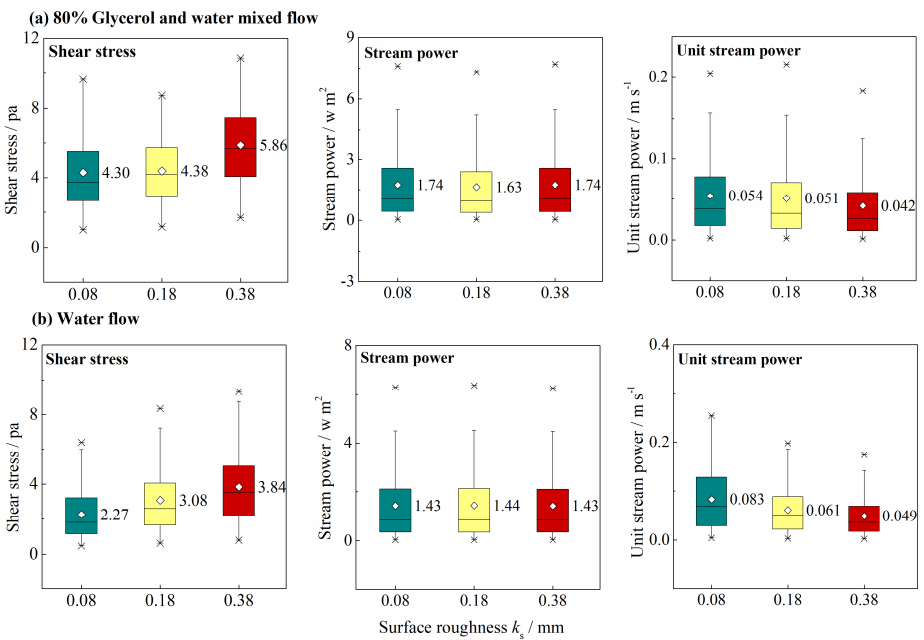

Note: The upper and lower edges of boxes indicate 80 th and 25 th percentiles, the horizontal lines within boxes indicate median value, the upper/lower short lines extended from the box edges indicate 1.5 fold the interquartile range, and the rhombic markers indicate mean value.

Fig. 9 Summary estimation of the shear stress, stream power and unit stream power associated with three surface roughnesses 

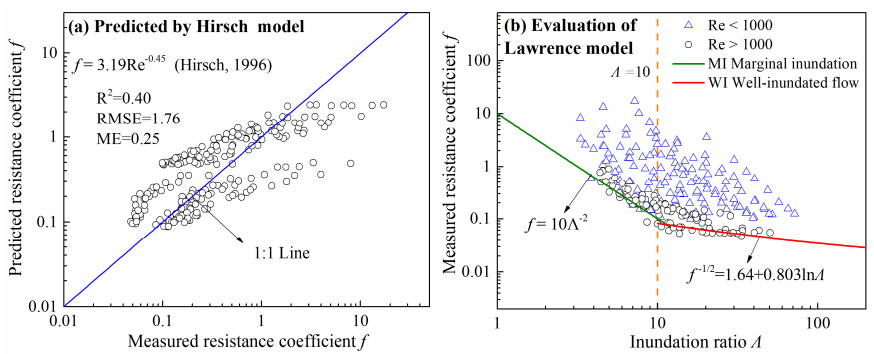

Fig. 10 Evaluation of two widely used models based on experimental data of this study

\section{Hosted file}

Table1. doc available at https://authorea.com/users/313584/articles/444353-overland-flow-hydrodynamiccharacteristics-at-low-reynolds-number-with-roughness-bed

\section{Hosted file}

Table2. doc available at https://authorea.com/users/313584/articles/444353-overland-flow-hydrodynamiccharacteristics-at-low-reynolds-number-with-roughness-bed

\section{Hosted file}

Table3.doc available at https://authorea.com/users/313584/articles/444353-overland-flow-hydrodynamiccharacteristics-at-low-reynolds-number-with-roughness-bed 